\title{
The relationship between difficulties in psychological adjustment in young adulthood and exposure to bullying behaviour in childhood and adolescence
}

\author{
Kristina Sesar ${ }^{1}$, Marijana Barišić ${ }^{2}$, Maja Pandža ${ }^{2}$, Arta Dodaj $^{2}$
}

${ }^{1}$ Centre of Mental Health

Široki Brijeg Health Care Centre, Široki

Brijeg, Bosnia and Herzegovina

${ }^{2}$ Department of Psychology

University of Mostar, Mostar

Bosnia and Herzegovina

Corresponding author:

Kristina Sesar

Centre of Mental Health, Široki Brijeg

Health Care Centre

Dr. J. Grubišića 11

88220 Široki Brijeg

Bosnia and Herzegovina

kristina.sesar@tel.net.ba

Tel.: + 38739703870

Fax.: + 38739704936

Received: 9 June 2012

Accepted: 15 October 2012

Copyright (c) 2012 by

Academy of Sciences and Arts

of Bosnia and Herzegovina.

E-mail for permission to publish:

amabih@anubih.ba

\begin{abstract}
Objective. This study investigates the relationship between involvement in bullying in childhood and adolescence and psychological difficulties in young adulthood. Materials and method. A total of 249 college students completed the Retrospective Bullying Questionnaire and Trauma Symptom Checklist. Results. The results showed significant differences in psychological adjustment among respondents who were exposed to bullying compared to respondents who were not exposed to bullying. Those exposed to bullying had significantly higher levels of anxiety, depression, sleeping problems, and dissociative and traumatic symptoms compared to those who were not exposed to bullying. Respondents who were exposed to bullying in all three examined periods (the period from the first to fourth grade, the period from the fifth to eighth grade and the high school period) had higher scores on the subscale of dissociative symptoms and sexual trauma symptoms compared to respondents who were exposed through one or two periods. Victims abused in all three periods have more symptoms of anxiety and sleeping problems compared to the subjects exposed to bullying during one examination period. There were no differences in the level of depressive symptoms and sexual problems regarding the duration of bullying. Also, there were no differences in psychological adjustment between respondents who were bullied during one specific period. Conclusion. Bullying experiences in childhood and adolescence are connected with difficulties in psychological adjustment in young adulthood.
\end{abstract}

Key words: Bullying, Psychological adjustment, Young adulthood, Trauma symptoms, Retrospective research.

\section{Introduction}

Bullying is not a new phenomenon. Different forms of bullying have existed as long as schools. Almost all adults have childhood memories or experiences of bullying in different situations, whether they acted aggressively towards other children, experienced bullying themselves or witnessed bullying. Many adults, regardless of age, are still able to recall details of these events, such as the name of the school bully, classes they attended, duration of exposure to bullying and so on. In a study that was conducted by Crozier and Skliopidou (1), among 220 adults, who were asked about their memo- 
ries related to the period when they were in primary school, it was established that two thirds of adults recalled that they were exposed to mockery or derogatory names.

Respondents who were exposed to bullying, stated that these events were accompanied by feelings of anger, shame and unhappiness. Recollection of these events and the derogatory names they were called are still painful for one fourth of the questioned participants and they believe that these experiences caused long-lasting negative effects on the development of their personalities and attitudes.

There is no single common definition of bullying, but most agree that there are factors that should be taken into consideration such as: firstly, different patterns of behavior that are repeated over time with the intent to hurt or disturb one or more students by one or more other students; secondly, there must be a perceived imbalance of power between the bully and the victim, which allows one student to dominate over others (2). Situations where there is a conflict between individuals of equal or similar power are not considered bullying. This distinction is important because the consequences of repeated attacks or threats by individuals or groups more powerful than themselves, most likely differ from the effects of exposure to threats or attacks by someone of the same strength. In the first case individuals feel helpless (3).

In different ways, psychologists tried to determine the varieties of forms of bullying amongst children. In certain studies, bullying amongst children is conceived globally (4). For example, as an action that aims to threaten someone or to hurt someone who is weaker. In other studies (5) distinctions were made between the different types of aggressive acts or behaviors that may be performed, for example, physically, verbally or indirectly. The distinction can also be made depending on whether a child is abused by one individual or by a group. Someone can be abused because they belong to a group which the bully does not approve of or because of some personal characteristics. Finally, we also distinguish exposure to bullying in one or several situations as opposed to long term exposure to bullying. All these distinctions are very important especially when talking about the consequences of bullying (3).

Numerous studies show that bullying is a worldwide problem. Studies conducted in Australia, Canada, UK, Japan, Scandinavia and Croatia, indicate that $20 \%$ to $30 \%$ of school children participate in bullying (6-14). When we take into account the frequency of bullying in regard to the role in bullying behavior, the research results show that $7-23 \%$ of respondents were identified as bullies, $5-12 \%$ as victims and $2-21 \%$ of respondents as bully/victims (7, 15-18). Studies in this field have demonstrated that children exposed to bullying are more likely to experience a wide range of adverse psychosocial and behavioral outcomes (19-21).

Most of the studies are focused on shortterm consequences of peer victimization (22). Among the wide range of negative consequences associated with bullying, special attention is focused on the development of depressive disorders (22, 23-26), and suicidal thoughts and ideas in children exposed to bullying (27-29). One of the most common emotional responses to prolonged exposure to bullying are different forms of anxiety disorders such as social and chronic anxiety (22, 30-33). In children exposed to violent behavior, symptoms of PTSD were also identified. The above stated symptoms can manifest as behavioral problems, avoiding school, the class and persons associated with bullying, and loss of interest in people, imposed memories of traumatic events, nightmares, frightening memories of one or more traumatic events (34-36). Physical symptoms such as headaches, stomachaches, 
back pain, chest tightness, sore throat, sleeping problems, morning fatigue, poor appetite and night urination are often associated with exposure to bullying (23, 29, 37-38).

However, cross-sectional studies are not able to provide evidence for something more than correlations among bullying and psychological difficulties. A small number of studies investigated the long-term consequences of bullying. The results of longitudinal studies are consistent with the results of the intersection of research and suggest that exposure to bullying is correlated with different forms of internalizing and externalizing psychological problems $(8,30,39-$ 41). A prospective study by Schreier et al. (42) showed associations between adverse experiences in childhood and psychotic symptoms in adulthood. Furthermore, prospective types of studies have shown that history of victimization predicts the onset of emotional problems in the early teen years (43).

However, most longitudinal studies that have been conducted so far have focused on shorter periods of time and still lack longitudinal studies through longer period of time (39). Moreover, a shortcoming of longitudinal and prospective studies is that the data are collected over a specific period of time, and rarely cover the entire childhood (44). Also, this type of research is expensive current and because of that researchers are directed towards the implementation of retrospective studies. Retrospective studies of bullying conducted so far are rare and mainly focus on specific populations (3, 45-46). They suggest a correlation between victimization and difficulties in heterosexual relationships, declaring that they were exposed to bullying behavior in childhood. In a study conducted on 276 adults (aged 15-66) in England who were exposed to child abuse, approximately one half of the participants reported that they had a long-term psychological effects, most commonly in the field of personal relationships (46). In a retrospective study conducted on adult subjects (3) it was discovered that men exposed to victimization at school had interpersonal difficulties, resulting in fear of intimacy and shyness, which limits them in creating a satisfying intimate relationship with the opposite sex. Allison, Roeger and Reinfeld-Kirkman (47) investigated the relationship between past victimization and adult health-related quality of life. In a representative sample of Australian adults experience in bullying was determined by interview. Furthermore, the health-related quality of life was measured using the Medical Outcomes Study 36item ShortForm Health Survey. The results showed that those who had been bullied experienced significantly poorer mental and physical health compared to those who had not been bullied.

Retrospective studies which researched exposure to bullying in the student population, indicate that the subjects who were exposed to bullying in childhood and adolescence were more likely to develop depressive disorders $(39,48-49)$, anxiety disorders (49-50, 51-52) and difficulties in interpersonal relationships (53-54) compared to students who did not have such experiences. Furthermore, Ronning et al. (55) found that frequent bullying is a marker of present and later psychopathology.

The duration of exposure to violent behavior is another significant factor in the development of long-term psychological consequences in individuals exposed to violent behavior (54). Students who reported that they were exposed to bullying through the period of both the lower and upper grades of primary school were more likely to develop psychological problems compared to those who were exposed to bullying in one of these two periods (during the lower grades of elementary school or only in the higher grade) (54). 
Although these studies provide some evidence of the specific effects of being bullied, most of these studies (42-43) do not extend into later adolescence. It is important to know the effects of being bullied during the period of the lower and upper grades of primary school, as well as high school on later adolescent functioning. To our knowledge this is the first study that includes a retrospective investigation of different periods of bullying on psychological functioning of adolescents. This could have important implications for the possibility of identifying the critical period when bullying has the strongest effects on adolescent behavior. Furthermore, the studies conducted examine specific psychological difficulties that could be the result of being bullied. Studies also need to account for all co-existing difficulties that could appear simultaneously in bullied children. Finally, to explore whether bullying has an impact on adolescent behavior and mental health, it is important to include a not bullied comparison group. Most of these studies examine the association between bullying and some types of psychological difficulties. It is methodologically more appropriate to categorize subjects into different categories with regard to experience in bullying.

The aim of this study was to examine the association between exposure to bullying during childhood and adolescence and difficulties in psychological adjustment amongst young adults.

\section{Methods}

\section{Participants}

The study includes 249 students from different departments of the Faculty of Humanities and Social Sciences, University of Mostar, (173 females and 76 males). The average age of the participants was $21.3 \pm 3.14$. These students were in different years of study and academic specialization, including social work, psychology, and philosophy. The par- ticipants were provided with an information sheet that outlined the main principles of the research and contact information if they wished to contact the researchers later on. They were given time to read the information sheet and to ask questions. The study was approved by the Ethics Committee of Mostar University and by The Ministry of Science, Education, and Sports of HerzegovinaNeretva Canton, Bosnia and Herzegovina.

\section{Instruments}

For the purpose of this study a questionnaire was constructed with sociodemographic data. The questionnaire included data on student sex, age, type and year of study. The exposure to bullying among children in primary and secondary schools was examined through the Retrospective Bullying Questionnaire (RBQ), which was constructed by Schäfer et al. (54). The implementation of the questionnaire in this study was approved by the authors of the questionnaire. For the purpose of this study, the questionnaire was translated into Croatian and adapted through the technique of reverse translation. It was translated from English to Croatian and then afterwards from Croatian into English. After this procedure, the verification of the translated version was done by two independent experts in the field of bullying and after their alignment, the final version was made.

The questionnaire contained 44 questions, mostly multiple choice. It covered experiences of victimization in school (six types of victimization, two physical, two verbal, two indirect), and specifically their frequency, severity, and duration (all 5-point scales), gender, the number of bullies (six options), and the students' participation in active bullying. These questions were asked firstly for primary school and then for secondary school. This was followed by a 5 -item trauma subscale of intrusive and recurrent recollections of victimization (each 5-point 
scales), and a question on suicidal ideation if bullied (4-point scale). The last part of the questionnaire included questions about the frequency, intensity and duration of abuse in the workplace. However, this part of the questionnaire was not an appropriate form for a group of students, so we decided to modify the questionnaire and to reduce the questions. The questionnaire was introduced by a definition of bullying. The anonymity of the questionnaire was stressed, and a detachable sheet of advice, helplines and some useful websites were given at the end for those who might wish to discuss their experiences further. The criterion for classification of students as bullies was based on the confirmatory answers to questions relating to how they abused their peers and how frequently it occurred. As for the classification of the victims, confirmatory answers in the first part of the questionnaire related to exposure to, as well as experience of frequent abuse, were the criteria for classification. The victim group was further divided into subgroups regarding the period of exposure to bullying: the period from first to fourth grade (approximate age range - 6 to 10 years), the period from the fifth to eighth grade (app. age - 10 to 15 years) and the high school period (app. age - 15 to 19 years).

In previous studies in which this measure instrument was used, the authors did not specify the factor structure $(54,56)$. This is reasonable because the questionnaire examines different aspects of bullying, in which responses are expressed on a continuous scale. Schäfer et al. (54) reported reliability of 0.88 for testing the scale of bullying in elementary school, 0.87 for the examination of bullying in high school, and 0.77 for exposure to bullying and the strategies used to cope with bullying.

Psychological adjustment in young adulthood was assessed by the Trauma Symptom Checklist 40 (TSC-40) (57). TSC-40 is used to determine the symptomatology in adults who experienced trauma in either childhood or adult age. It measures aspects of post-traumatic stress and other symptoms that occur in traumatized individuals. TSC-40 is a 40 item self-reporting instrument. In addition to yielding a total score, it has six subscales: Anxiety, Depression, Dissociation, Sexual Abuse Trauma Index, Sexual Problems, and Sleep Disturbances. For each item of the scale, the respondents are asked to rate the frequency of symptom occurrence during the preceding two months, using a Likert-type scale from 1 ("never") to 4 ("often"). Briere (58) found that the coefficients of internal consistency subscale range from 0.66 to 0.77 (58). In this study, coefficients of internal consistency range from 0.64 to 0.73 , and the reliability of the entire scale is 0.90 . Satisfactory levels of reliability justify the use of existing subscales in subsequent analyzes.

\section{Data collection}

Data were collected in the summer semester of 2012 during lectures. Questionnaires were group applied (the study units) and were not limited in time. On average they took 15 minutes. In the instructions to the participants, the anonymity of data was emphasized and it was explained how to fill the questionnaire. Each participant first filled out the questionnaire with sociodemographic data, while the sequence of filling out the Retrospective Bullying Questionnaire and the Trauma Symptoms Checklist - 40 was rotated by the principle of ABBA. Thus, half of participants first filled out the Retrospective Bullying Questionnaire, and the Trauma Symptoms Checklist - 40, while the other half of participants worked in the reverse order.

\section{Data analysis}

Statistical analysis was performed using Statistica 7.0 (StatSoft, Inc., Tulsa, OK, USA). Depending on the distribution of the vari- 
ables, the Student t-test or the Mann-Whitney test was used to determine the difference in psychological adjustment between the neutral group (not exposed to peer abuse) and victims (exposed to peer abuse). Using the one-way ANOVA and Kruskal-Wallis tests, victims ' psychological adjustment was additionally analyzed depending on the period of peer abuse. The Bonfferoni correction test for multiple testing and multiple comparisons of mean ranks for all groups were applied where it was necessary. P-values less than 0.05 were considered significant.

\section{Results}

In analyzing the results, we first defined the term 'victim' for our sample. We then considered differences of our outcome measures. Our primary interest was in victim/ non-victim differences. Victims $(\mathrm{N}=119)$ were identified from their responses about the frequency and intensity of reported physical, verbal and indirect bullying. A person was considered a victim when they reported being bullied in one or more ways 'sometimes' or more (frequency) and classified this as 'quite serious' or 'extremely serious' (intensity).

Respondents who were assessed to have never been exposed to bullying or those who indicated that they were exposed to bullying sometimes or rarely were categorized as neutral. Analysis of the results of the Retrospective Bullying Questionnaire showed that $44.1 \%$ out of the 119 participants were sometimes or frequently exposed to one or more forms of bullying. Verbal forms of bullying are the most common during elementary school (lower grades- 21.5\%; higher grades $-19.9 \%$ ), while indirect forms of bullying become more frequent in high school (17.9\%), compared to periods in elementary school. Physical forms of bullying are somewhat less frequent, ranging from 2.9\% at high school, to $8.1 \%$ and $11.8 \%$ at lower and higher grades of elementary school, respectively. Respondents were most exposed to bullying during one of the examined periods $(50.4 \%)$. During the two examined periods $48(40.3 \%)$ respondents were exposed to bullying. Throughout all three periods 21 subjects $(17.6 \%)$ were exposed to bullying.

Significant differences were established between respondents who were exposed to bullying and those who were not exposed to bullying in all measures of psychological adjustment. Respondents exposed to bullying had higher levels of symptoms of anxiety, depression, dissociative disorders, sleeping problems, sexual problems and higher levels of traumatic symptoms associated with sexual abuse (Table 1). The range of average differences in scores on the subscales achieved between the abused and the neutral group was lowest on the subscale of sexual difficulties and highest on the depression subscale.

When we took into account the duration of exposure to bullying, differences in the levels of psychological difficulties between the two groups were established (Table 2).

Respondents who were exposed to bullying in all three periods had higher scores on the subscale of dissociative symptoms $(\mathrm{M}=7.45 ; \mathrm{SD}=3.531)$ than respondents exposed to bullying during one $(M=4.63$; $\mathrm{SD}=2.863)$ or two periods $(\mathrm{M}=5.46 ; 2.887)$, $\mathrm{F}(2,113)=6.277, \mathrm{p}=0.003$. Also, being exposed to bullying through all three periods was connected with having more sexual trauma symptoms $(\mathrm{M}=6.63 ; \mathrm{SD}=3.989)$ compared to being exposed through one $(\mathrm{M}=3.36 ; \mathrm{SD}=2.595)$ or two periods $(\mathrm{M}=4.44 ; \quad \mathrm{SD}=3.148), \mathrm{F}(2,113)=7.469$, $\mathrm{p}<0.001$. Victims of bulling through all three periods had more symptoms of anxiety $(\mathrm{N}=7$, range of $4-8)$ than those bullied through one period $(\mathrm{N}=4$, range of 2-7), $\mathrm{F}(2, \mathrm{~N}=114)=7.128, \mathrm{p}=0.028$. Likewise, respondents who were bullied through all periods had more sleeping problems $(\mathrm{N}=6$, range of 4-8) than those who were exposed 
Table 1 Differences in psychological adjustment among respondents exposed to bullying and those who were not exposed to bullying

\begin{tabular}{lllll}
\hline \multirow{2}{*}{ Psychological difficulties } & \multicolumn{2}{l}{ Exposure to bullying } & \\
\cline { 2 - 5 } & Exposed & Not exposed & $\mathrm{t} / \mathrm{Z}$ & $\mathrm{P}$ \\
\hline Dissociation $(\bar{X} \pm$ SD) & $5.45 \pm 3.13$ & $4.02 \pm 2.61$ & 3.867 & $<0.001 \dagger$ \\
Anxiety (Median; range) & $6(3-8)$ & $4(2-7)$ & 2.565 & $0.01 \neq$ \\
Depression $(\bar{X} \pm$ SD) & $7.17 \pm 4.14$ & $5.06 \pm 3.19$ & 4.362 & $0.008 \dagger$ \\
Sexual abuse trauma index $(\bar{X} \pm$ SD) & $4.37 \pm 3.28$ & $2.91 \pm 2.32$ & 3.949 & $<0.001 \dagger$ \\
Sleep disturbances $($ Median; range) & $5(3-8)$ & $3(2-6)$ & 4.358 & $<0.001 \neq$ \\
Sexual problems $(\bar{X} \pm$ SD) & $3.84 \pm 3.27$ & $2.81 \pm 2.83$ & 2.550 & $0.011 \dagger$ \\
\hline
\end{tabular}

†Student t-test; $¥$ Mann-Whitney $U$ test.

Table 2 Differences in psychological adjustment in respondents exposed to bullying in regard to the duration of exposure to bullying (all three periods, combination of two periods, one period)

\begin{tabular}{llllll}
\hline \multirow{2}{*}{ Psychological difficulties } & \multicolumn{2}{l}{ Duration of exposure to bullying } & & \\
\cline { 2 - 6 } & One period & Two periods & Three periods & $\mathrm{F} / \mathrm{H}$ & $\mathrm{P}$ \\
\hline Dissociation $(\bar{X} \pm$ SD $)$ & $4.62 \pm 2.86$ & $5.46 \pm 2.89$ & $7.45 \pm 3.53$ & 6.277 & $0.002 \dagger$ \\
Anxiety (Median; range) & $5(3-8)$ & $6(3-8)$ & $9(5-15)$ & 7.128 & $0.028 \neq$ \\
Depression $(\bar{X} \pm$ SD) & $6.68 \pm 3.18$ & $7.13 \pm 4.07$ & $8.87 \pm 6.39$ & 1.606 & $0.205 \dagger$ \\
Sexual abuse trauma index $(\bar{X} \pm$ SD) & $3.36 \pm 2.59$ & $4.44 \pm 3.15$ & $6.63 \pm 3.99$ & 7.469 & $<0.001 \dagger$ \\
Sleep disturbances (Median; range) & $4(3-6)$ & $5(3-8.5)$ & $8(5-12)$ & 7.299 & $0.001 \neq$ \\
Sexual problems $(\bar{X} \pm$ SD) & $3.76 \pm 2.70$ & $3.74 \pm 2.89$ & $4.38 \pm 5.38$ & 0.247 & $0.781 \dagger$ \\
\hline
\end{tabular}

†ANOVA; ‡Kruskal-Wallis ANOVA.

Table 3 Differences in psychological adjustment in respondents exposed to bullying during one specific period

\begin{tabular}{|c|c|c|c|c|c|}
\hline \multirow[b]{2}{*}{ Psychological difficulties } & \multicolumn{5}{|c|}{ Duration of exposure to bullying } \\
\hline & $\begin{array}{l}\text { Lower grades } \\
\text { (elementary school) }\end{array}$ & $\begin{array}{l}\text { Higher grades } \\
\text { (elementary school) }\end{array}$ & High school & $\mathrm{F} / \mathrm{H}$ & $P$ \\
\hline Dissociation $(\bar{X} \pm S D)$ & $4.50 \pm 2.39$ & $5.44 \pm 3.37$ & $3.75 \pm 2.80$ & 1.236 & $0.300+$ \\
\hline Anxiety (Median; range) & $5(1-9)$ & $7(0-14)$ & $4(1-11)$ & 1.543 & $0.462 \neq$ \\
\hline Depression $(\bar{X} \pm S D)$ & $6.24 \pm 2.41$ & $8.20 \pm 3.78$ & $5.45 \pm 3.05$ & 2.974 & $0.061 \dagger$ \\
\hline $\begin{array}{l}\text { Sexual abuse trauma index } \\
(\bar{X} \pm \text { SD })\end{array}$ & $3.1 \pm 2.40$ & $4.23 \pm 3.00$ & $2.83 \pm 2.41$ & 1.083 & $0.348+$ \\
\hline $\begin{array}{l}\text { Sleep disturbances } \\
\text { (Median; range) }\end{array}$ & $7(0-10)$ & $6(1-10)$ & $3(0-8)$ & 4.237 & $0.439 \neq$ \\
\hline Sexual problems $(\bar{X} \pm S D)$ & $3.71 \pm 2.26$ & $4.21 \pm 3.74$ & $3.20 \pm 1.81$ & 0.406 & $0.669 \neq$ \\
\hline
\end{tabular}

†ANOVA; ¥Kruskal-Wallis ANOVA. 
to bullying during one period $(\mathrm{N}=3$, range of 2-5), $\mathrm{F}(2, \mathrm{~N}=114)=10.299, \mathrm{p}=0.006$. There were no differences in the level of depressive symptoms and sexual difficulties regarding the duration of bullying.

The levels of psychological difficulties of groups who were exposed to bullying during one period (lower/higher grades of elementary school, high school) were compared. This was done in order to try to isolate a possible critical period when more difficulties occurred (Table 3). However, no differences were found.

\section{Discussion}

The results of this study support the conclusions of previous studies $(8,48)$ which established the correlation between exposure to bullying during childhood and adolescence and psychological difficulties in young adulthood. According to the results of this research, $44.1 \%$ respondents were exposed occasionally or frequently to bullying during childhood and adolescence. Retrospective studies that have been conducted until now on college students have found that many of them recalled their experiences of bullying during school age. In a survey conducted of 119 college undergraduates, $48.7 \%$ of respondents reported that they were bullied at least once or twice; $15.1 \%$ reported they were bullied occasionally, and $2.5 \%$ stated that they were bullied frequently during high school (59). Newman et al. (60) found a higher rate of occasional and frequent bullying than the percentage found in the study by Chapell et al. (59). In a sample of 853 college students, Newman et al. (60) found that $24 \%$ of the respondents reported that they were occasionally bullied during high school and $9.1 \%$ recalled that they were frequently bullied during high school. These prevalence figures are higher than those obtained in school-based surveys, which often ask for reports of the last 3 or 6 months (61). This is in line with what might be expected from these school based surveys, if we take into account reports over the whole duration of education.

According to the results of this study, considering the data related to duration of bullying, respondents were most exposed to bullying during one of the indicated periods (42\%). $40.3 \%$ of respondents were exposed to bullying during two periods examined. In this case, these were the lower and higher grades of elementary school (24.4\%). 21 respondents (17.6\%) were exposed to bullying throughout all three periods. In this study, the established frequency of exposure to abuse, taking into account the duration of bullying, was significantly higher than in the research of Schäfer et al. (54).

In above mentioned study, $28 \%$ of respondents reported being victimized at school. Also, about half of these victims reported relatively extended victimization, lasting for months or longer, and about $8 \%$ of them reported being victimized in both primary and secondary school (54). The differences that were found between our study and the already mentioned research are not surprising. The study by Schäfer et al. (54) was conducted in Spain, Britain and Germany and it lasted longer. Furthermore during that study preventive work was systematically implemented. The main aim of these prevention programs was to reduce the occurrence of bullying. In Bosnia and Herzegovina and even in the region, research into bullying is in its initial stages as are the prevention programs. Moreover, in our region, a large number of children are not even aware of behaviors that are considered as bullying and are not aware of the negative consequences of such behavior, which directly affects its frequency. This study has shown that those young people who were exposed to bullying during their years of education reported more depressive symptoms compared to those who did not experience abuse during primary and secondary school. 
These results are in line with the results of retrospective studies conducted so far, in which respondents were exposed to bullying during their childhood and/or adolescence and consequently developed a higher risk of depressive disorders (48-49, 62-63).

Other than the symptoms related to depression, young people who were exposed to bullying in childhood and adolescence, reported a greater number of anxiety symptoms compared to those who were not. In studies conducted so far dealing with a retrospective examination of bullying, we found that the students who reported being victims of bullying also had symptoms associated with anxiety (50-52). Similarly, according to the results of Gladstone et al. (52) adult men who were exposed to bullying once a week for five or more years, had their current anxiety symptoms attributed to their abuse experience. In addition, respondents who were exposed to bullying during childhood and/or adolescence reported the symptoms of anxiety disorders earlier than those who did not report the experience of bullying $(50,52)$.

Cognitive theory gives us an insight into how the process of internalization of bullying events could potentially contribute to eventual long-term effects, such as depression and anxiety. According to this theory, the meaning one ascribes to events determines the affective response (64). If this tendency toward negative internalization persists, then these individuals may be at greater risk for depression, anxiety, and or problems in relationships (65-67). In Beck's example (65) of a young boy being teased by his friends, he provided an illustration of how internal evaluation of an event can be influential in determining emotional responses. In this example, Beck stated that objective meaning might be that his friends were simply joking with him. The boy's internal evaluation might be that he is "a weakling" or "they don't like me" (Beck, p. 48). Because these internal evaluations, or private meanings, are often regarded as embarrassing, the individual is less likely to examine these beliefs with others. Without the opportunity for others to challenge such thoughts, these negative perceptions about the self may persist and continue to influence beliefs about the self. Since children and adolescents who were targets of bullying are more likely to be socially isolated $(48,68-69)$ these individuals may be particularly unlikely to have such negative perceptions disconfirmed by others. In contrast, those with other opportunities to build social competence may be more likely to demonstrate resilience as they have additional opportunities to have these negative beliefs dispelled by others. Also drawing from cognitive theory (65-67), those low in competence or lacking other sources of developing competence may develop negative schemas associated with social experiences. New social experiences during college that remind one of these earlier, aversive experiences with peers may trigger negative social schemas, eliciting emotions, thoughts, images, and behavioral impulses associated with these earlier, aversive situations (70). Such interpretations may reinforce anxiety associated with social situations. Being the target of bullying also may contribute to a sense of learned helplessness (71), a cognitive pattern often displayed by individuals with depression (72). Those individuals who do not possess opportunities for developing competence may be more prone to learned helplessness. As victims may believe that they are unable to stop the bullying, they may also begin to believe that their efforts to affect the outcomes of other situations will be ineffective (49). If bullying persists for a long period of time, targets of bullying may begin to generalize this sense of incompetence to other areas of their lives, which may lead to low self-esteem and a greater likelihood of developing depression and anxiety during college years (73).

According to the results of some studies (74) there is evidence that suggests that 
there is a possible connection between bullying in schools and post-traumatic stress disorder. To our knowledge, this is one of the first studies to investigate the long-term traumatic consequences of exposure to bullying, and also a wide range of traumatic symptoms. The analysis of the obtained results showed that the respondents who were exposed to bullying, besides the symptoms of anxiety and depression, had more pronounced sleeping problems, dissociative symptoms and SATI than those who were not bullied. Whether we focus on the individual symptoms or analyze them together, these symptoms are a measure of the trauma (75-76). A significant correlation was determined between the abuse and trauma symptoms, which indicates that bullying as a form of violent behavior is a traumatic experience for people who are exposed to it (77). The time that elapsed from the first experience of abuse to the moment of the research may complicate the distinctions of the different forms of abuse (physical, verbal or relational), but nevertheless, the obtained results illuminate the potentially traumatic nature of bullying. If we are to truly understand the association between psychological difficulties and experiences of bullying, it is necessary to consider other potential factors that may contribute to the development of long-term psychological difficulties. The duration of such an experience is one of the potential risk factors $(54,60,63)$. In this study we found that respondents who were exposed to abuse during all three periods of education had higher scores on the subscale of dissociative symptoms and the subscale for the assessment of traumatic symptoms associated with sexual abuse than those who were exposed to bullying in one or two of the studied periods. Furthermore, respondents who were exposed to bullying in all three periods had higher levels of anxiety and more sleeping problems than those abused in only one period.
Comparison of the results of psychological difficulties in those exposed to bullying in one and two periods showed that the lowest scores on the subscales of dissociation, anxiety, sexual trauma and sleep difficulties were seen in those with the shortest duration of bullying. However, although these differences are significant, they are quite small compared to the group which was bullied through all three periods of interest.

These results are consistent with the results of the retrospective studies by Newman et al. (60) conducted on 853 students. The later one stated that the greater frequency and longer duration of abuse in childhood and adolescence is associated with increased stress symptoms. Schäfer et al. (54) found that the duration of peer victimization is a risk factor that seems to have an impact on the development of long-term consequences. Students who reported that they were exposed to bullying in the lower and higher grades of elementary school had more psychological difficulties than those who were abused in only one of these periods (54). Kochenderfer and Ladd (78) found that the duration of the victimization experience was associated with the magnitude of difficulties in psychological adaptation in persons exposed to bullying. Unlike the results of other studies $(8,22,48,63)$ which showed that the length of time of bullying may relate to the development of depression in later life, in our study we did not distinguish the difference in symptoms of depression caused by different durations of bullying.

In addition to analyzing the duration of bullying, psychological difficulties were analyzed regarding the specific time period in which bullying occurred. However, no differences in levels of psychological difficulties were found. Psychological difficulties are associated with being exposed to bullying, regardless of the period in which it happened. It must be noted, however, that levels of depression in specific bullying periods are near 
the critical value of significance $(\mathrm{F}=2.974$, $\mathrm{p}=0.061$ ). This could imply that there could be some specific critical period when bullying victims are at higher risk of having symptoms of depression in later life. To support this, a meta-analysis of longitudinal studies performed by Ttofi et al. (79) shows that the level of depression is to be expected to be lower, if the student was younger when the bullying happened. Future studies with a larger sample are needed in this country, investigating the relationship between specific periods and the later occurrence of depression to see if the results confirm the findings of Ttofi et al. After this the implications of such results may be found.

The differences between our study and other studies of the symptoms of depression can be justified by the difference in the way we analyzed the data. In our study, the respondents were divided into categories according to the duration of bullying. After that, we made comparisons between categories considering the duration of bullying. In other studies, the length of bullying and its correlation to the symptoms of depression were considered, without making comparisons between the respondents who were exposed to bullying on the basis of the duration of bullying. Rigby and Slee (80) attempted to explain why the length of bullying affects the shape and magnitude of psychological difficulties. They suggest that the attitudes of the environment become less supportive as children become older. It may be that children, who were abused for a longer period of time and were treated in a less friendly manner than their peers while growing up, are consequently at greater risk for later psychological difficulties.

\section{Limitation of research}

The limitation of our study is mostly related to its retrospective design. The data collected from students was of a private nature and required them to recall negative experi- ences from childhood. Some negative experiences may have been repressed and forgotten, whereas others could have been exaggerated. The limitation associated with the retrospective design is that the cause cannot be established from the results. It is possible that those who were bullied may possess other characteristics that made them vulnerable to bullying (e.g., poor social skills, shyness, etc.) and that these characteristics have persisted into adulthood, making them more prone to depression, anxiety, and loneliness (81). Future research should focus on testing mediation effects. The demographic characteristics of the sample should also be taken into consideration when examining the results. There were significantly more females than males. This sample closely reflects the gender distribution at the Faculty of Humanities and Social Sciences at the University of Mostar. These findings may not be representative of other faculties and colleges with different gender distribution.

\section{Conclusion}

The results of this study support the results of some previous studies where it was determined that exposure to bullying during childhood and adolescence may have an influence on the development of long-term consequences on mental health, including the increased risk of developing depression, anxiety, post-traumatic stress and difficulties in interpersonal relationships $(22,54$, $60,63,74)$. The identified psychological difficulties are similar or identical to the symptoms identified in children who are currently exposed to bullying $(33,73,81-82)$. This indicates that the consequences of bullying may persist until young adulthood. These results indicate that bullying is not a separate phenomenon but is associated with psychopathology. Therefore, it is important for college counseling professionals to be aware of the consequences of bullying in late adolescence and young adulthood, as this may 
strengthen their understanding of how these early traumatic experiences may influence the current functioning of the individuals.

Authors' contributions: Conception and design: KS, $\mathrm{MB}, \mathrm{MP}$ and $\mathrm{AD}$; Acquisition of data: $\mathrm{MB}, \mathrm{MP}$ and $\mathrm{AD}$; Analysis of data: MP and AD; Interpretation of data: MP, AD and KS; Drafting the article: KS, MP and MB.

Conflict of interest: The authors declare that they have no conflict of interest. This study was not sponsored by any external organization.

\section{References}

1. Crozier WR, Skliopidou E. Adult recollections of name-calling at school. Educ Psychol. 2002;22(1):113-24.

2. Rivers I, Duncan N, Besag VE. Bullying: A handbook for educators and parents. Westport: Greenwood/Praeger; 2007.

3. Rigby K. Consequences of bullying in schools. Can J Psychiatry. 2003;48:583-90.

4. Holzbauer JJ, Berven NL. Disability harassment: A new term for a long-standing problems. J Couns Dev. 1996;74(5):478-83.

5. Crick NR, Grotpeter JK. Relational aggression, gender and social psychological adjustment. Child Dev. 1995;66:710-22.

6. Dake JA, Price JH, Telljohann SK. The nature and extent of bullying at school. J Sch Health. 2003;73(5):173-80.

7. Forero R, McLellan L, Rissel C, Bauman A. Bullying behavior and psychosocial health among school students in New SouthWales, Australia: cross sectional survey. BMJ. 1999; 319:344-8.

8. Kumpulainen K, Rasanen E. Children involved in bullying at elementary school age: their psychiatric symptoms and deviance in adolescence. An epidemiological sample. Child Abuse Negl. 2000;24:1567-77.

9. Nansel TR, Overpeck M, Pilla RS, Ruan WJ, SimonsMorton B, Scheidt P. Bullying behaviors among US youth: prevalence and association with psychosocial adjustment. JAMA. 2001;285:2094-100.

10. Wolke D, Woods S, Bloomfield L, Karstadt L. Bullying involvement in primary school and common health problems. Arch Dis Child. 2001;85(3):197-201.

11. Craig WM, Pepler D, Atlas R. Observations of bullying in the playground and in classroom. School Psychol Int. 2000;21:22-36.

12. Rios-Ellis B, Bellamy L, Shoji J. An examination of specific types of ijime and their prevalence within Japanese schools. School Psychol Int. 2000;21(3):227-41.

13. Salmivalli C, Lagerspetz K, Bjőrkqvist K, Österman $\mathrm{K}$, Kaukianen A. Bullying as a group process: participant roles and their relations to social status within group. Aggressive Behav. 1996;22:1-15.

14. Radman - Petrušić K. Nasilništvo i strategije suočavanja kod djece osnovnoškolske dobi [diplomski rad]. Zagreb: Odsjek za psihologiju filozofskog fakulteta u Zagrebu; 2005.

15. Juvonen J, Graham S, Schuster MA. Bullying among young adolescents: the strong, the week, and the troubled. Pediatrics. 2003;112(6 Pt 1):1231-7.

16. Mazur J, Malkowska A. Bullies and victims among Polish school-aged children. Med Wieku Rozwoj. 2003;7(1 Pt 2):121-34.

17. Yang SJ, Kim JM, Kim SW, Shin IS, Yoon JS. Bullying and victimization in boys and girls at South Korean primary schools. J Am Acad Child Adolesc Psychiatry. 2006;45(1):69-77.

18. Ivarsson T, Bronberg AG, Arvidsson T, Gillberg C. Bullying in adolescence: Psychiatric problems in victims and bullies as measured by the Youth Self Report (YSR) and the Depression Self-Rating Scale (DSRS). Nord J Psychiatry. 2005;59:365-73.

19. Herrenkohl TI, Sousa C, Tajima EA, Herrenkohl RC, Moylan CA. Intersection of child abuse and children's exposure to domestic violence. Trauma Violence Abus. 2008;9:84-99.

20. Sternberg KJ, Baradaran LP, Abbot CB, Lamb ME, Guterman E. Type of violence, age, and gender differences in the effects of family violence on children's behavior problems: A mega-analysis. Dev Rev. 2006;26:89-112.

21. Wolfe DA, Crooks CV, Lee V, McIntyre-Smith A, Jaffe P. The effects of children's exposure to domestic violence: A meta-analysis and critique. Clin Child Fam Psych. 2003;6:171-87.

22. Hawker DSJ, Boulton MJ. Twenty years' research on peer victimization and psychosocial maladjustment: a meta-analytic review of cross-sectional studies. J Child Psychol Psychiatry. 2000;41:441-55.

23. Fekkes M, Pijpers FI, Verloove-Vanhorick SP. Bullying behavior and associations with psychosomatic complaints and depression in victims. J Pediatr. 2004;144:17-22.

24. Kaltiala-Heino R, Rimpela M, Marttunen M, Rimpela A, Rantanen P. Bullying, depression, and suicidal ideation in Finnish adolescents: school survey. BMJ. 1999;319:348-51.

25. Klomek AB, Marrocco F, Kleinman M, Schonfeld IS, Gould MS. Bullying, depression, and suicidality in adolescents. J Am Acad Child Psych. 2007;46(1):40-9. 
26. van der Wal MF, de Wit CA, Hirasing RA. Psychosocial health among young victims and offenders of direct and indirect bullying. Pediatrics. 2003;111:1312-7.

27. Kaltialo-Heino R, Rimpela M, Marttunen M, Rimpela A, Ratenen P. Bullying, depression and suicidal ideation in Finnish adolescents: school survey. BMJ. 1999;319:348-50.

28. Kim YS, Koh YJ, Leventhal B. School bullying and suicidal risk in Korean middle school students. Pediatrics. 2005;115:357-63.

29. Williams K, Chambers M, Logan S, Robinson D. Association of common health symptoms with bullying in primary school children. BMJ. 1996;313:17-9.

30. Bond L, Carlin JB, Thomas L, Rubin K, Patton G. Does bullying cause emotional problems? A prospective study of young teenagers. BMJ. 2001;323(7311):480-4.

31. Kumpulainen K. Psychiatric conditions associated with bullying. Int Journal Adolesc Med Health. 2008;20(2):121-32.

32. O'Moore AM, Hillery B. What do teachers need to know? In: Elliott M, editor. Bullying: A Practical Guide to Coping in Schools. Harlow: David Fulton; 1991. p. 56-69.

33. Craig WM. The relationship among bullying, victimization, depression, anxiety, and aggression in elementary school children. Pers Indiv Differ. 1998;24:123-30.

34. Rivers I, Cowie H. Bullying and homophobia in U.K. schools: A perspective on factors affecting resilience and recovery. JGLED. 2006;3:11-43.

35. Rivers I, Duncan N, Besag VE. Bullying. Handbooks for educators and parents. Westport, Connecticut, London: Praeger Publisher; 2007.

36. Sharp S. How much does bullying hurt? The effects of bullying on personal well-being and educational progress of secondary aged students. Educ Child Psychol. 1995;12:81-8.

37. Due P, Holstein BE, Lynch J, Diderichsen F, Gabhain SN, Scheidt $P$, et al. Health Behaviour in School-Aged Children Bullying Working Group. Bullying and symptoms among school-aged children: international comparative cross sectional study in 28 countries. Eur J Public Health. 2005;15(2):128-32.

38. Rigby K. The relationship between reported health and involvement in bully/victim problems among male and female secondary school students. J Health Psychol. 1998;3(4):465-76.

39. Storch EA, Ledley DR. Peer victimization and psychosocial adjustment in children: Current knowledge and future directions. Clin Pediatr. 2005;44(1):29-39.

40. Haavisto A, Sourander A, Multimaki P, Parkkola K, Santalahti P, Helenius H, et al. Factors associated with depressive symptoms among 18-yearold boys: a prospective 10-year follow-up study. J Affect Disord. 2004;2-3:143-54.

41. Kim YS, Leventhal BL, Koh YJ, Hubbard A, BoyceWT. School bullying and youth violence: causes or consequences of psychopathologic behavior? Arch Gen Psychiatry. 2006;63:1035-41.

42. Schreier A, Wolke D, Thomas K, Horwood J, Hollis C, Gunnell D, et al. Prospective Study of Peer Victimization in Childhood and Psychotic Symptoms in a Nonclinical Population at Age 12 Years. Arch Gen Psychiatr. 2009;66:527-36.

43. Bond L, Carlin JB, Thomas L, Rubin K, Patton G. Does bullying cause emotional problems? A prospective study of young teenagers. Brit Med J. 2001;323:480-84.

44. Hardt J, Rutter M. Validity of adult retrospective reports of adverse childhood experiences: review of the evidence. J Child Psychology Psyc. 2004;45(2):260-73.

45. Gilmartin BG. Peer group antecedents of severe love-shyness in males. J Pers. 1987;55:467-89.

46. Hugh-Jones S, Smith K. Self-reports of short and long term effects of bullying on children who stammer. Brit J Educ Psychol. 1999;69:141-58.

47. Allison S, Roeger L, Reinfeld-Kirkman N. Does school bullying affect adult health? Population survey of health-related quality of life and past victimization. Aust NZ J Psychiat.2009;43:1163-70.

48. Olweus D. Victimization by peers: antecedents and long term outcomes. In: Rubin $\mathrm{KH}$, Asendorf JB, editors. Social Withdrawal, Inhibition, and Shyness in Children. Erlbaum: Hillsdale, NJ; 1993.

49. Roth DA, Coles ME, Heimberg RG. The relationship between memories for childhood teasing and anxiety and depression in adulthood. J Anxiety Disord. 2002;16:149-64.

50. McCabe RE, Antony M, Summerfeldt L, Liss A, Swinson R. Preliminary examination of the relationship between anxiety disorders in adults and self-reported history of teasing or bullying experiences. CBT. 2003;32:187-93.

51. Dempsey AG, Stroch EA. Relational victimization: The association between recalled adolescent social experiences and emotional adjustment in early adulthood. Psychol Schools. 2008;45(4):310-22.

52. Gladstone GL, Parker GB, Malhi, GS. Do bullied children become anxious and depressed adults? A cross-sectional investigation of the correlates of bullying and anxious depression. J Nerv Ment Dis. 2006;194(1-3):201-8. 
53. Ledley DR, Stroch EA, Coles, ME, Heimberg RG, Moser J, Bravata EA. The relationship between childhood teasing and later interpersonal functioning. J Psychopathol Behav. 2006;28:33-40.

54. Schäfer M, Korn S, Smith PK, Hunter SC, MoraMerchán J, Singer MM, et al. Lonely in the crowd: Recollections of bullying. Brit J Dev Psychol. 2004;22(3):379-94.

55. Ronning JA, Sourander A, Kumpulainen K, Tamminen T, Niemela S, Moilanen I, et al. Crossinformant agreement about bullying and victimization among eight year olds: Whose information best predicts psychiatric caseness 10-15 years later? Soc Psychiatry Psychiatr Epidemiol. 2009;44(1):15-22.

56. Mora-Merchán JA. Coping strategies: mediators in long-term effects of victims of bullying? Annuary of Clinical and Health Psychology. 2006;2:15-25.

57. Briere JN, Runtz, MG. The Trauma Symptom Checklist (TSC-33): Early data on a new scale. J Interpers Violence. 1989;4:151-63.

58. Briere J. Trauma Symptom Checklist for Children (TSCC) Professional Manual. Odessa, FL: Psychological Assessment Resources; 1996.

59. Chapell MS, Hasselman SL, Kitchin T, Lomon SN, Maclver KW, Sarullo PL. Bullying in elementary school, high school, and college. Adolescence. 2006;41:633-48.

60. Newman ML, Holden GW, Delville Y. Isolation and the stress of being bullied. J Adolescence. 2005;45:343-57.

61. Smith PK Madsen K, Moody J. What causes the age decline in reports of being bullies in school? Towards a developmental analysis of risks of being bullied. Educ Res. 1999;41:267-85.

62. Storch EA, Roth DA, Coles ME, Heimburg RG, Bravata EA, Moser J. The measurement and impact of childhood teasing in a sample of young adults. J Anxiety Disord. 2004;18:681-94.

63. Jantzer AM, Hoover JH, Narloch R. The relationship between school-aged bullying and trust, shyness, and quality of friendship in young adulthood: A preliminary research note. School Psychol Int. 2006;27:146-56.

64. Beck AT. Thinking and depression: II. Theory and therapy. Arch Gen Psychiatry. 1964;10:561-71.

65. Beck AT. Cognitive therapy and the emotional disorders. New York: International Universities Press; 1976.

66. Beck AT, Emery G, Greenberg RL. Anxiety disorders and phobias. A cognitive perspective. New York, NY: Basic Books; 1985.

67. Beck AT, Rush JA, Shaw BF, Emery G. Cognitive therapy for depression. New York: Guliford Press; 1979.
68. Boulton MJ, Trueman M, Chau C, Whitehand C, Amataya K. Concurrent and longitudinal links between friendship and peer victimization: Implications for befriending interventions. J Adolesc. 1999;22:461-6.

69. Espelage DL, Swearer SM. Research on school bullying and victimization: what have we learned and where do we go from here? School Psychol Rev. 2003;32(3):365-83.

70. Brewin CR. Cognitive change processes in psychotherapy. Psychol Rev. 1989;96:379-94.

71. Besag V. Bullies and Victims in Schools: A Guide to Understanding and Management. Philadelphia: Open University Press; 1989.

72. Abrahamson LY, Seligman, Teasdale M. Learned Helplessness in Humans: Critique and Reformulation. J Abnorm Psychol. 1978;87:49-74.

73. Smokowski PR, Holland K. Bullying in School: Correlates, Consequences, and Intervention Strategies for School Social Workers. Children \& Schools. 2005;27(2):101-10.

74. Rivers I. Recollections of bullying at school and their long-term implications for lesbians, gay men and bisexuals. Crisis. 2004;24:169-75.

75. Briere J, Runtz M. Symptomatology associated with childhood sexual victimization in a nonclinical adult sample. Child Abuse Neglect. 1988;12:51-9.

76. Elliott DM, Briere J. Sexual abuse trauma among professional women: Validating the Trauma Symptom Checklist-40 (TSC-40). Child Abuse Neglect. 1992;16:391-8.

77. Herman JL. Father-daughter incest. Cambridge, MA: Harvard University Press; 1981.

78. Kochenderfer BJ, Ladd GW. Peer victimization: Cause of consequence of school maladjustment? Child Dev. 1996;67:1305-17.

79. Ttofi MM, Farrington DP, Lösel F, Loeber R. Do the victims of school bullies tend to become depressed later in life? A systematic review and meta-analysis of longitudinal studies. J of Aggression, Conflict and Peace Research. 2011;3:63-73.

80. Rigby K, Slee PT. Bullying among Australian school children: reported behaviour and attitudes to victims. J Soc Psychol. 1991;131:615-27.

81. Ledley D, Stroch E, Coles M, Heimberg R, Moser J, Bravata E. The Relationship between childhood teasing and later interpersonal functioning. J Psychopathol Behav. 2006;28:33-40.

82. Andreou E. Bully/victim problems and their association with psychological constructs in 8-to 12year old Greek school-children. Aggressive Behav. 2000;26:49-56. 